\title{
Nasal dorsal aesthetic lines and rhinoplasty technical tricks
}

\author{
Alexander Kutubidze \\ Department of Aesthetic Plastic Surgery, Esthetic Service Clinic, Tbilisi 0171, Georgia. \\ Address for correspondence: Dr. Alexander Kutubidze, Department of Aesthetic Plastic Surgery, Esthetic Service Clinic, Tbilisi 0171, Georgia. \\ E-mail: akutubidze@aol.com
}

\begin{abstract}
Rhinoplasty surgery remains one of the most difficult operations of the face. Improving aesthetic appearance and maintaining nasal function are inseparable goals in rhinoplasty surgery, and failure to achieve either of these objectives can be devastating for the patient. After evaluating a variety of rhinoplasty complications, increased attention was devoted to the surgical technique for reconstruction of the dorsal aesthetic lines and nasal tip projection in the patient with a prominent dorsal hump. Based on the modern concept of cartilage conservation, the autospreader flap rotation technique should be considered when dorsal reduction is required. Autospreader flaps are a useful tool in the prevention of postoperative nasal obstruction, segmental (inverted V) appearance, midfacial axial asymmetry and an overdone supratip break. In addition, they assist in preserving ethnicity of the nose when desired. The patient with a long nose, prominent dorsal hump, short nasal bones and low lower lateral cartilages are considered to be an ideal candidate for an autospreader flap.
\end{abstract}

\section{Key words:}

Autospreader flap, nasal aesthetic anatomy, nasal dorsal aesthetic lines, open rhinoplasty, spreader graft

\section{INTRODUCTION}

The greatest challenge in primary aesthetic rhinoplasty is the application of advanced anatomical, aesthetic and ethnic principles to an individual case, thereby customizing the procedure to achieve the most natural result for the patient-individualized treatment plan. ${ }^{[1,2]}$ Specific factors to be noted during the preoperative assessment for the optimization of aesthetic results include the patient's ethnicity, gender, nasofacial aesthetic and any specific requests. The endonasal (closed) and external (open) techniques are the two main techniques used in both primary and secondary rhinoplasty. ${ }^{[3,4]}$ With both approaches, the goals are to preserve or achieve normal airflow while delivering an aesthetically pleasing and natural permanent long-term result. Multiple studies have reported that nasal obstruction is a relatively common problem in patients

\begin{tabular}{|l|l|}
\hline \multicolumn{2}{|c|}{ Access this article online } \\
\hline Quick Response Code: & Website: \\
\hline & www.parjournal.net \\
\cline { 2 - 3 } & \\
\hline
\end{tabular}

presenting for aesthetic rhinoplasty, with a high prevalence of nasal deviation. ${ }^{[5]}$ The functions of the nose, specifically respiration, humidification, filtration, temperature regulation and protection, are regulated by the septum, turbinates and nasal valves (internal and external)..$^{5,6]}$

Therefore, every rhinoplasty surgeon should cultivate a full understanding of intranasal and external nasal anatomy, the differential diagnosis for nasal obstruction, and the elements of a complete nasal examination, including nasal endoscopy. In addition, a comprehensive analysis of the face and a broad understanding of the long-term effects of healing forces on the ultimate nasal aesthetic and function are required..$^{[5]}$ Knowledge of rhinoplasty medical and surgical treatment options and side effects anatomical correlates can assist in anticipating them intraoperatively

This is an open access article distributed under the terms of the Creative Commons Attribution-NonCommercial-ShareAlike 3.0 License, which allows others to remix, tweak, and build upon the work non-commercially, as long as the author is credited and the new creations are licensed under the identical terms.

For reprints contact: reprints@medknow.com

How to cite this article: Kutubidze A. Nasal dorsal aesthetic lines and rhinoplasty technical tricks. Plast Aesthet Res 2015;2:315-9.

Received: 21-10-2014; Accepted: 22-10-2015 
in certain surgical maneuvers. Patient safety is optimized with the use of specific surgical procedures, protocols, specialized instruments and staff training. Endotracheal monitored anesthesia care is preferable and a nasopharyngeal pack can be a useful preventative measure by helping to keep the larynx clear.

\section{THE AESTHETIC ANATOMY OF THE NOSE: DORSAL AESTHETIC LINES}

The bony cartilaginous pyramid of the external nose is three-dimensional structure composed of three basic regions: the upper rigid bony third, the middle semi-rigid cartilaginous third and the lower mobile cartilaginous third. Nasal deformities result from the loss of support to this tripod [Figure 1]..$^{[4]}$

The soft tissue components of the nose include skin, muscles, nerves and vascular tissues. The tissue layers and fibrovascular membranous structures of the skin envelope in the inferior part of the external nose are divided into five layers, which are similar to the structure of the face: epidermis, dermis, superficial fascia, fibromuscular layer and perichondrium. The thin, dynamic musculoaponeurotic layer of the nose is a critical structure of the nose. Preservation of this layer is vital in restoring and retaining nasal function and appearance. ${ }^{[8-10]}$

The nasal dorsum connects the radix to the lateral projections of the crura of the lower lateral cartilages (LLCs) by means of two diverging concave lines. These are the nasal dorsal aesthetic lines, which are unbroken extensions of the superciliary ridges [Figure 2]. The radix and supratip regions have thicker soft tissue coverage, while the midvault area contains thinner tissue. The supratip break occurs cephalad to the nasal tip where the contour lines of the nasal dorsum rise toward the tip-defining points. The tip-defining points are composed of two equilateral triangles which extend from the supratip region to the apex of the domes to the columellar lobule angle..$^{[8,11,12]}$ To achieve a balanced dorsal profile with a supratip break, it is necessary to create a frame with a slightly deeper nasion and tip projection beyond the dorsum. ${ }^{[10-13]}$ From an aesthetic standpoint, the area from the nasal bridge

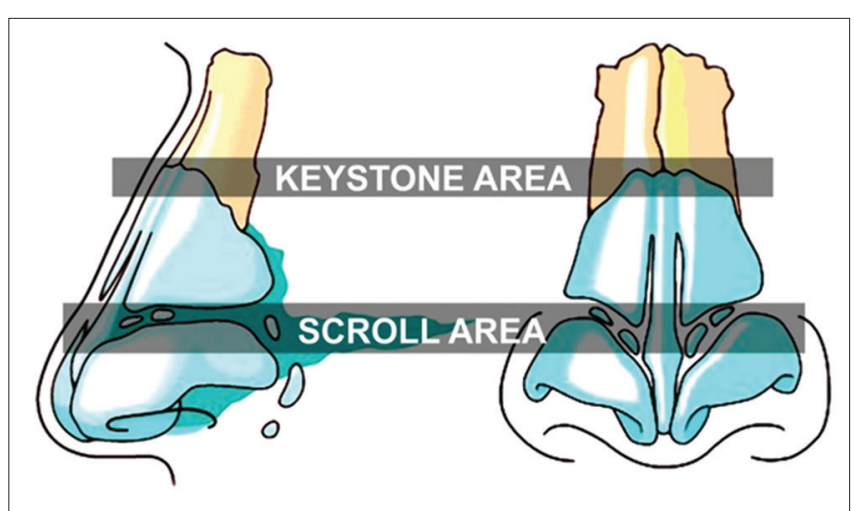

Figure 1: The keystone area, where the nasal bones overlap the upper lateral cartilages and the scroll area, where the lower lateral cartilages overlap the upper lateral cartilages. Restoration of the keystone area anatomical structure during the primary rhinoplasty prevents open roof and inverted $\mathrm{V}$ deformities to nasal tip should be aligned and straight. ${ }^{[14,15]}$ Over reduction of the dorsum can change the orbito-nasal relationship with subsequent flattening of the midface.

\section{COMPLICATIONS OF RHINOPLASTY}

Clinical manifestations of complications of rhinoplasty and side effects may be classified as functional, aesthetic, or both. A number of technical solutions have been presented. ${ }^{[4,5,12,16]}$ After a review of these potential complications, specific attention was directed to the surgical technique for reconstruction of nasal tip projection and the dorsal aesthetic lines in the patient with a prominent dorsal hump. Functional insufficiency of the internal nasal valve occurs in conjunction with the inverted $\mathrm{V}$ deformity (with disruption of the dorsal aesthetic lines) caused by collapse of the upper lateral cartilages following removal of the dorsal hump. This combined complication can be prevented during component reduction of the dorsal hump by avoiding excessive resection of the upper lateral cartilage as compared with the septum (midvault area) and by placement of spreader grafts. ${ }^{[17]}$

The nasal tip presents an exceptional challenge because of its mobility. ${ }^{[12-15]}$ During dorsal hump reduction when the K-area is disrupted and not aligned with the nasal bridge, it may act as a pivot point; downward and inward rotation of the septal cartilage then becomes possible, disproportionally widen the nasal dorsum and result unnatural look of dorsal aesthetic lines. Protrusion of the anterior septal cartilage can create a polly beak deformity. The polly beak deformity is remarkable for protuberance with a rounded downward pointing tip and fullness of the supratip region. Excess scar tissue in the region of the dorsal septal cartilage or supratip may become apparent once edema has resolved and is more likely to occur in patients with thicker skin. The deformity can be prevented by maintaining adequate tip support through columellar struts. In addition, suturing the subcutaneous tissue of the supratip to the caudal

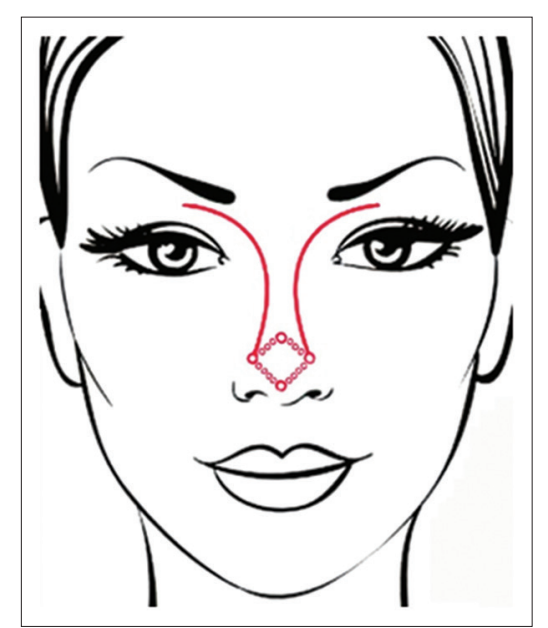

Figure 2: The dorsal aesthetic lines originate on the supraorbital ridges and pass medially along the glabellar area to converge caudally at the medial canthal ligaments. From there, they usually begin diverging at the keystone area and ultimately conclude at the tip-defining points, which become the highest point in the nasal profile 
dorsum and scroll areas eliminates dead space and formation of deep scar tissue, thereby preserving the functional and aesthetic anatomy of the nose. ${ }^{[10-14]}$

Systematic and complete analysis of external and internal nasal anatomical regions and knowledge of normal variants are critical factors in creating an appropriate operative plan for a successful rhinoplasty. ${ }^{[5,6]}$

\section{THE SURGICAL PLAN AND OPERATIVE STRATEGIES}

Open rhinoplasty is an increasingly preferred approach for primary and secondary rhinoplasty in the practices of most experienced rhinoplasty surgeons. ${ }^{[4]}$ Both approaches provide the surgeon with the ability to successfully perform rhinoplasty, but each has its appropriate anatomical indications, advantages and disadvantages. The most significant advantage of open rhinoplasty approach is improved surgical exposure with better visualization for surgical maneuvers. Direct observation of the underlying bony cartilaginous framework permits accurate diagnosis of nasal deformities, as well as precise manipulation of the dorsum and the nasal tip through a variety of technical maneuvers. ${ }^{[14-16]}$ Dissection below the musculoaponeurotic layer preserved the major arterial, venous and lymphatic channels. ${ }^{[6,10]}$ The integrity of the nasal lobule and minor tip support mechanisms can be preserved, preventing future loss of tip projection, and grafts can be fashioned and secured without fear of displacement. This degree of precision can decrease uncontrolled scarring of tissues and lower the rate of revision. Negative consequences of open rhinoplasty include external scarring, occasional prolonged tip edema and longer surgical time. However, the transcolumellar scar typically heals well and is not noticeable. Tip edema generally resolves without negative consequences when using subperichondrial dissection and suturing techniques..$^{\mid 6,10,14,15]}$

\section{AUTOSPREADER FLAP TECHNIQUE}

Following reduction of the bony and cartilaginous dorsum, spreader grafts can be placed. Sheen's spreader graft concept remains the gold standard for internal valve reconstruction and has been applied for surgical restoration of the disrupted nasal dorsum. ${ }^{[16,18]}$ The need for a spreader graft is an important consideration during all primary rhinoplasty cases. ${ }^{[4]}$ Patients with a high, narrow dorsum, a weak middle vault, short nasal bones or a positive Cottle test preoperatively are at higher risk for developing postoperative internal nasal valve dysfunction and resultant nasal airway obstruction. . $^{[6,8,16,18]}$ Traditionally, spreader grafts are fashioned from cartilage taken from the septum or ear. ${ }^{[16-18]}$ Disadvantages of the use of spreader grafts include increased operative time and donor site morbidity. ${ }^{[16,18]}$ Postoperative swelling following submucosal dissection of the septum can be both considerable and unpredictable. In all cases, it is crucial to maintain a $10-15 \mathrm{~mm}$ L-strut of cartilage along the nasal dorsum and caudal septum. The width of the nasal dorsum is typically wider after spreader grafts have been applied..$^{[4,5]}$

Another option involves the autospreader flap, in which the upper lateral cartilage and septum are preserved. Surgical time is reduced while maintaining the dorsal aesthetic lines and internal valve function. ${ }^{16,18]}$ Oneal and Berkowitz were among the first to utilize the upper lateral cartilages as spreader grafts, and they coined the term "spreader flap". ${ }^{[16,18-20]}$ Gruber et al. ${ }^{[16]}$ subsequently referred to this maneuver as an "autospreader flap".

If a hump is at least $3 \mathrm{~mm}$ above the ideal dorsal line, it is usually possible to fold the dissected ends of the upper lateral cartilages as local flaps at their interface with the septum. ${ }^{[18]}$ The upper lateral cartilage excess can be appreciated following precise reduction of the septum and bony hump. Autospreader flaps are bilaterally interposed between the septum and upper lateral cartilages, including the portion lying under the nasal bones. Where the hump is minimal and folding over the cartilages is not possible, it may be an option to simply return the upper lateral cartilages to the dorsum with suture fixation. With the use of asymmetric mattress sutures, the autospreader flaps are positioned horizontally, abutting the septum instead of being vertically folded and fixed to the septum. ${ }^{[10,16]}$ Preservation of the dynamic musculoaponeurotic system with its ligamentous connections permits their repair at the time of closure. Repair of Pitanguy's midline ligament using advancement suture allows the surgeon to control tip rotation, enhance projection, and emphasize a supratip break, while reconstruction of the scroll area ligaments provides stability of the internal nasal valve..$^{[7,10,11]}$ Utilization of the cartilage from the reduced dorsal septum permits successful reshaping of the middle vault and nasal tip. The resected cartilage fragment may also be used as a columellar strut, which thereby allows us to again forego the standard septal harvest, reducing operative time and patient morbidity. ${ }^{[21]}$ The ideal patient for this technique requires $3 \mathrm{~mm}$ or more of dorsal hump reduction, and should not have any breathing problems or septal deviation that would require septal surgery. It is important to identify the patient with a tension tip, as he or she will certainly require maintenance or restoration of tip projection to prevent a polly beak deformity.

The cartilage-conserving concept can be efficient and aesthetic in well-selected patients, but as always anatomical differences will dictate the surgical approach. ${ }^{[22,23]}$ Upon follow-up, patients demonstrate better postoperative recovery, with much less septal swelling and proportional projection of the dorsal aesthetic lines without over-widening at the K-area. The most common problem encountered is the technique's inability to provide adequate dorsal width when compared to spreader grafts. In addition, the use of an autospreader flap has not been described for special cases such as the crooked nose, small dorsal humps, and in secondary cases. Therefore, relative contraindications to use this 
technique include those with a deviated dorsal septum, asymmetric dorsal aesthetic lines, and upper lateral cartilages of insufficient length at caudal end of the septum. This population likely benefit from traditional spreader grafts harvested from the nasal septum, perhaps combined with autospreader flaps. The thickness of free septal grafts can be varied to control asymmetry. In the appropriate patient with nasal axial deviation who also requires a septoplasty, the combined use of autospreader flaps and unilateral or bilateral spreader grafts may be indicated to correct asymmetric dorsal aesthetic lines. Indications for the use of both techniques include widening of the dorsal middle third of the nose (especially in ethnic cases), bridging and strengthening a long, narrow roof of the middle nose in patients with short nasal bones and high LLCs, straightening and stabilizing a dorsally deviated septum, and creating ethnically acceptable dorsal aesthetic lines [Figure 3]. Nasal septal grafts are thicker and stronger, resisting the deforming forces of a deviated septum and thus correcting the curvature. ${ }^{[18]}$ Autospreader flaps alone may not provide adequate stability when there is associated collapse of the bony sidewalls. In these instances, traditional spreader grafts that extend beyond the keystone are indicated. For cases in which an autospreader flaps cannot provide sufficient width at the anterior septal angle, this area must be supported by spreader grafts [Figure 4].

\section{CONCLUSION}

The patient with a long nose, prominent dorsal hump, short nasal bones and low LLCs are good candidates for an autospreader technique [Figure 5]. The technique is simple, reproducible and effective in shaping the dorsum while preserving the function of the internal valve in primary rhinoplasty patients. Subperichondrial dissection of the nasal framework with preservation of the dynamic musculoaponeurotic system and controlled manipulation and repair of ligaments without disturbing the overlying soft tissue allows reshaping and redraping of the nasal aesthetic lines.

The relation between anatomical form and function is of enduring interest in modern aesthetic plastic surgery, being central to our understanding of physiological systems. It provides lessons for engineering design based on advanced anatomical knowledge. For now, limited evidence available in PubMed that shows benefit of using spreader flap technique for correction of dorsal septal deviations. $^{\mid 24]}$ The use of a spreader flap technique has not been described for special cases with minimal dorsal humps and secondary cases. The spreader architecture rhinoplasty requires wider studies in compare and contrast flap and graft techniques to identify which technology provides the most benefit in terms of outcomes for more durable, consistent, predictable and harmonic results.

\section{Financial support and sponsorship}

Nil.

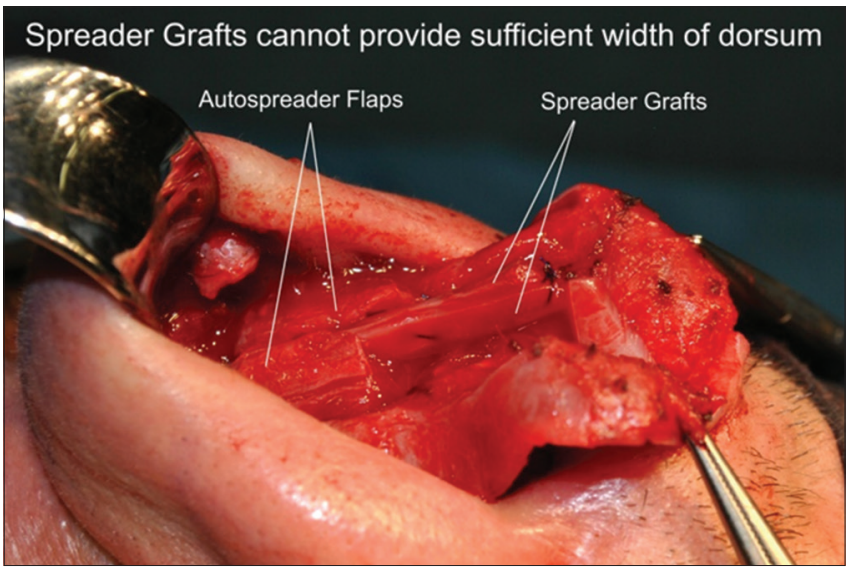

Figure 3: Combination use of the spreading grafting

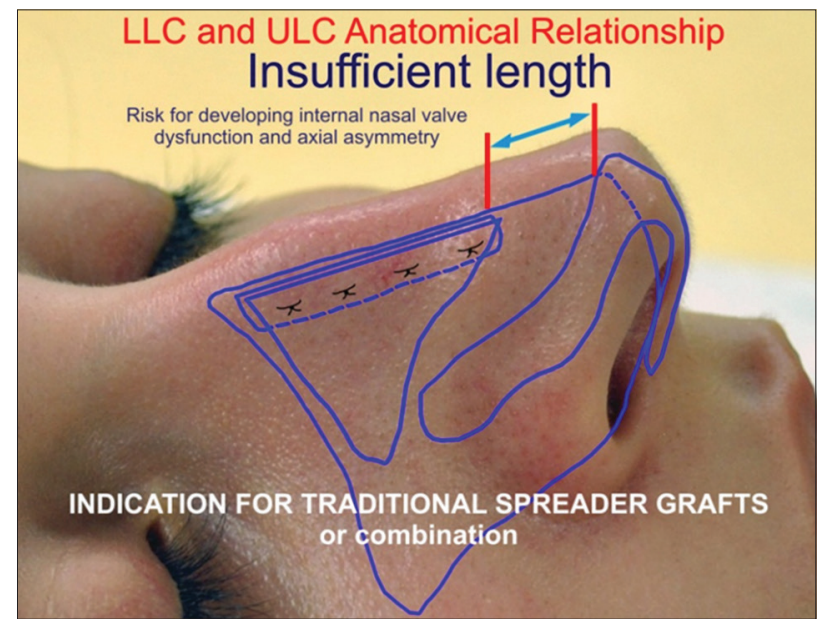

Figure 4: Indication for spreader graft procedure

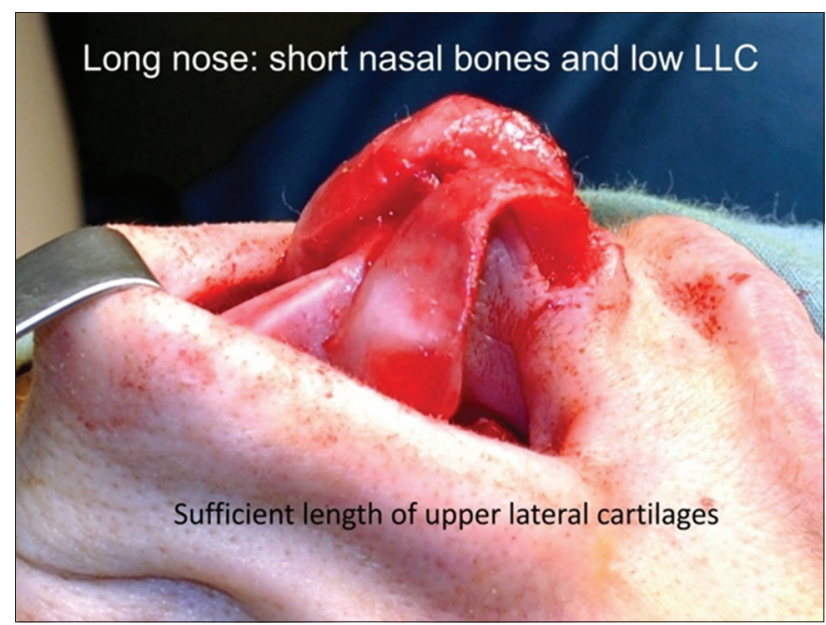

Figure 5: Indication for the autospreader grafting

\section{Conflicts of interest}

There are no conflicts of interest.

\section{REFERENCES}

I. Nahai F. Your favorite technique: time for a change? Aesthetic Surg J 2012;32:900-2.

2. Nahai F. Evidence-based medicine in aesthetic surgery. Aesthetic Surg J 201 I;31:I35-6.

3. Gunter JP, Hackney FL. Clinical assessment and facial analysis. In: Gunter JP, Rohrich RJ, Adams WP Jr, editors. Dallas Rhinoplasty: 
Nasal Surgery by the Masters. St. Louis: Quality Medical Publishing; 2002. p. 53-7l.

4. Sajjadian A, Guyuron B. Primary rhinoplasty. Aesthetic Surg J 20 10;30:527-39.

5. Becker DG, Ransom E, Guy C, Bloom J. Surgical treatment of nasal obstruction in rhinoplasty. Aesthetic Surg J 2010;30:347-78.

6. Guyuron B. Soft tissue functional anatomy of the nose. Aesthetic Surg J 2006;26:733-5

7. Palhazi P, Daniel RK, Kosins AM. The osseocartilaginous vault of the nose: anatomy and surgical observations. Aesthetic Surg J 2015;35:242-5I.

8. Rohrich RJ, Muzaffar AR, Janis JE. Component dorsal hump reduction: the importance of maintaining dorsal aesthetic lines in rhinoplasty. Plast Reconstr Surg 2004; I I 1:1298-308.

9. Wang ZJ, Wang N, Yang HM, Bai SL. Investigation of the layers and vascular density of the soft tissue in the inferior nasal portion. Zhonghua Zheng Xing Wai Ke Za Zhi 2007;23:65-8.

10. Cakir B, Oreroglu AR, Dogan T, Akan M. A complete subperichondrial dissection technique for rhinoplasty with management of the nasal ligaments. Aesthetic Surg J 20I2;32:564-74.

II. Kim SK, Kim JC, Lee KC, Kim HS. Correction of the supratip deformity of the nose. Aesthetic Surg J 2012;32:943-55.

12. Guyuron B, DeLuca L, Lash R. Supratip deformity: a closer look. Plast Reconstr Surg 2000; 105: I 140-5I.

13. Ponsky D, Eshraghi Y, Guyuron B. The frequency of surgical maneuvers during open rhinoplasty. Plast Reconstr Surg 2010;126:240-4.
14. Gruber RP, Weintraub J, Pomerantz J. Suture techniques for the nasal tip. Aesthetic Surg J 2008;28:92-100.

15. Daniel RK. Tip refinement grafts: the designer tip. Aesthetic Surg J 2009;29:528-37.

16. Gruber RP, Melkun ET, Woodward JF, Perkins SW. Dorsal reduction and spreader flaps. Aesthetic Surg J 20I I;31:456-64.

17. Sheen JH. Spreader graft: a method of reconstructing the roof of the middle nasal vault following rhinoplasty. Plast Reconstr Surg 1984;73:230-9.

18. Byrd HS, Meade RA, Gonyon DL Jr. Using the autospreader flap in primary rhinoplasty. Plast Reconstr Surg 2007; I 19:1897-902.

19. Manavbasi YI, Basaran I. The role of upper lateral cartilage in dorsal reconstruction after hump excision: section I. Spreader flap modification with asymmetric mattress suture and extension of the spreading effect by cartilage graft. Aesthetic Plast Surg 201 I;35:487-93.

20. Oneal RM, Berkowitz RL. Upper lateral cartilage spreader flaps in rhinoplasty. Aesthetic Surg J 1998; I8:370-I.

21. Rohrich RJ, Liu JH. The dorsal columellar strut: innovative use of dorsal hump removal for a columellar strut. Aesthetic Surg J 2010;30:30-5.

22. Aston SJ. A plastic surgeon's evolution. IPRAS J 20I I;(6):33-4.

23. Spiro SA, Wolfe SA, Wider TM. The use of the labiocolumellar crease incision in rhinoplasty. Ann Plast Surg 1996;37:569-76.

24. Yagmur C, Kelahmetoglu O, Akbas H. Spreader flap correction of dorsal septal deviations. Aesthetic Surg J 2015;35:345-8. 